\title{
Preparation and Analysis of Polar Hawthorn Berry Extracts, Industrial Application in Poultry Processing
}

\author{
Márta Kubovics', Said Al-Hamimi², György Huszár³, Kinga Komka1', \\ Charlotta Turner², Edit Székely
}

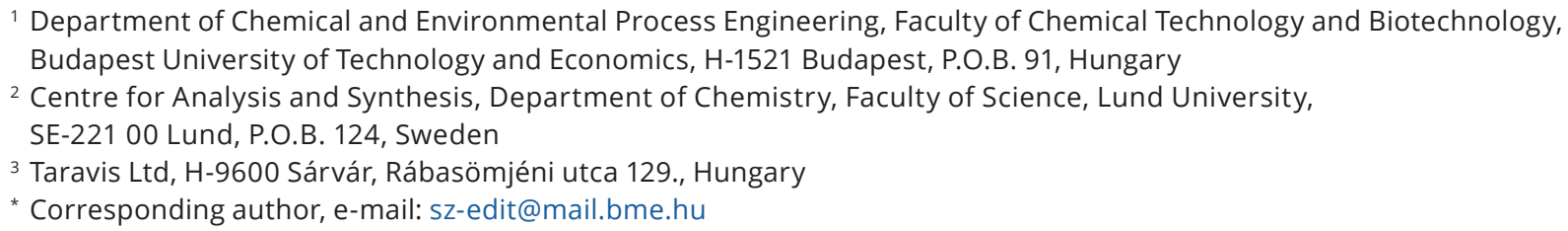

Received: 31 July 2018, Accepted: 30 October 2018, Published online: 29 March 2019

\begin{abstract}
For years, it is an actuality in the poultry processing industry, that the body and the cardiovascular system of the chickens are not strong enough due to the shortened rearing time. This induces, that the quality of the chicken breast is not appropriate for selling, since during the processing procedure, frequently blood spots appear inside the meat. These damaged parts need to be removed, causing huge economic loss. In this paper a solution for this problem is searched using hawthorn, a traditional herb, with well-known beneficial effects to the cardiovascular system. Improvement of the product quality and the reducing amount of the removed meat are supposed by applying a treatment with a polyphenol-rich drinking tincture made from the plant. Beside the preparation of the drinking liquid, including pretreatment, extraction and dilution steps, chemical analysis of the phenolic compounds is also conducted. The result of the drinking test shows that the extent of the blood spots, and thus the quantity of the "cut off" meat decreased significantly, however the reduction of the meat weight and a slight change in the death rate are also needed to take into consideration. It has been found, that the total phenolic contents of the berry are similar to literature data, while they show moderate antioxidant efficiency. Several phenolic acids, procyanidins and flavonoids were identified as the main phenol compounds of the applied extract.
\end{abstract}

\section{Keywords}

hawthorn, extraction, phenolics, poultry processing industry

\section{Introduction}

Hawthorn (Crataegus sp.) is a traditional herb - also native in Hungary - with well-known positive effects to the cardiovascular system [1]. The herb has been used commonly to prevent and treat chronic cardiovascular diseases, such as congestive heart failure, high blood pressure, hyperlipidemia, cardiac arrhythmia [2,3]. The presence of hawthorn products as nutriments (jams, juices, preserved fruits) shows the diverse utilization of the plant [4]. Besides human consumption several products are offered for animals, for example for elderly dogs or racing horses [5]. The pharmacological effects are attributed to the polyphenolic content of the herb [6, 7]. Phenolic acids, flavonoids, procyanidin oligomers and anthocyanins have been observed in the berries, flowers and leaves of the plant $[8,9]$. It has been reported, that the herb has the ability to increase the integrity of the blood vessel wall and improve the flow in the coronary blood [10].

We propose that the beneficial cardiovascular effect of the polar hawthorn extracts can also be utilized in an unusual field. In the poultry processing industry due to the shortened rearing time the bodies of the animals are not strong enough. According to the Animal Welfare Law, chickens are slaughtered after electrical stunning $[11,12]$. Due to the electric shock the not fully-fledged capillaries snap off in the chicken breast and blood spots appear inside the meat. These spots have to be removed necessarily before selling due to the need of the market. The value of the produced "cut off meat" is low compared to the most valuable part, the chicken breast fillet (average prices in 2015: $405 \mathrm{HUF} / \mathrm{kg}$ vs. $845 \mathrm{HUF} / \mathrm{kg}$ ). On the 
basis of the beneficial effect of plant to the cardiovascular system, it is supposed, that using hawthorn extracts as nutritional supplement, the integrity of the blood vessels of the chickens might be increased, therefore the extent of the blood spots inside the meat can be decreased.

Bioactive compounds of a herb might be extracted by various methods and solvents [5]. The targeted compound families are polar, thus polar solvents (water and ethanol, as well as well mixtures) are good candidates especially because they are GRAS (generally regarded as safe) solvents as well. Hawthorn berries on the other hand contain significant amount of non-polar components as well, including fatty acids, di- and triacylglycerols and -(lyso) phosphatidylcholines, which easily lead to formation of emulsion and foaming during a polar extraction [13, 14].

Supercritical $\mathrm{CO}_{2}$ extraction is typically applied to obtain non-polar components, oils and waxes from various matrices [15-17]. We used $\mathrm{scCO}_{2}$ extraction as pretreatment to reduce the amount of oily and fatty components and thus reduce the formation of emulsion and foaming in the hydroalcoholic extraction step.

Our aim is to show the benefits of feeding chickens with a tincture containing hawthorn extract in a sensitive period of one week in their 6 weeks long development. The analysis of the polar extracts, namely the determination of the total polyphenol, tannin, flavonoid content, the antioxidant efficiency and identification of the main phenolic compounds are also presented.

\section{Materials and methods}

\subsection{Materials}

Wild hawthorn berries were collected in November 2015 in Etyek region of Hungary. The berries were air dried to allow their storage. Ethanol (CAS 64-17-5, purity $96 \%$ ), methanol (CAS 67-56-1, purity > $99.8 \%$ ), aluminium-chloride (CAS 7446-70-0, anhydrous) were purchased from Molar Chemicals, Hungary. Carbon-dioxide (purity > $99.9 \%$ ) was brought from Linde Gas Hungary. Sodium-carbonate (CAS 497-19-8, purity > 99.8\%), pyrogallol (CAS 87-66-1, purity $>98 \%$ ), quercetin dihydrate (CAS 204-187-1, purity $>98 \%$ ), 2,2-diphenyl-1-picrylhydrazyl (CAS 1898-66-4), butylated hydroxytoluene (CAS 128-37-0, purity > $99 \%$ ), Folin-Ciocalteu reagent (CAS 5995-86-8) and hide powder were ordered from Sigma Aldrich Kft, Hungary. For the analysis of the phenolic compounds formic acid (CAS 64-18-6, LC-MS grade) were purchased from Fisher Scientific, USA; methanol (CAS 67-56-1, LC-MS grade), acetonitrile (CAS 75-05-8, LC-MS grade) from VWR chemicals, France.

\subsection{Preparation of the drinking tincture}

\subsubsection{Pretreatment of the plant}

The berries were grinded first using sieve diameter of $2 \mathrm{~mm}$ and then $1 \mathrm{~mm}$ (average particle size: $0.74 \pm 0.004 \mathrm{~mm}$, uniformity of the particles: $1.990 \pm 0.084$, based on particle size analysis carried out in triplicate.) (Cutting Mill pulverisette 15).

\subsubsection{Pilot scale supercritical $\mathrm{CO}_{2}$ extraction}

The grinded berries were processed in two portions. Approximately $1.5 \mathrm{~kg}$ of the powder were extracted once at $45 \mathrm{MPa}$ and $50{ }^{\circ} \mathrm{C}$. The separators were operating at 4 and $2 \mathrm{MPa}, 40{ }^{\circ} \mathrm{C}$. All extracts were collected from the first separator. The schematic flow diagram of the apparatus and the detailed description of the process were presented elsewhere $[18,19]$. The yield was calculated in percentage of $\mathrm{g}$ dry extract / $100 \mathrm{~g}$ dry plant. The residue of the berries was utilized in further extraction steps.

The extraction was carried out according to the following program:

- 3 times 26 minutes using 3 times $3 \mathrm{~kg}$ of $\mathrm{CO}_{2}$

- 3 times 34 minutes using 3 times $4 \mathrm{~kg}$ of $\mathrm{CO}_{2}$

- the system was kept under pressure for 1 hour for equilibration

- 2 times 34 minutes with 2 times $4 \mathrm{~kg}$ of $\mathrm{CO}_{2}$

- depressurization of the apparatus.

\subsubsection{Pilot scale Soxhlet extraction}

Pilot scale Soxhlet extraction with $96 \%$ ethanol was performed in order to prepare a polar extract (Fig. 1). Ethanol was selected to reduce the thermal degradation of the active components during the evaporation of the extraction solvent. The supercritical fluid extraction residue of the berries was processed in three portions. Approximately $1 \mathrm{~kg}$ of pretreated material was moistened with the extraction solvent and placed into the extractor. The solvent tank was also filled with ethanol, totally 4.5 litre was used. The extractor was operated at approximately $50{ }^{\circ} \mathrm{C}$. The process was running until the amount of the extract (taken from the flow after the extractor and measured after evaporation) was not decreasing permanently (approximately 6 hours). Finally, $\mathrm{CO}_{2}$ was flushed through the apparatus to evaporate as much solvent as possible. More detailed description of the process was published earlier [20]. The extraction was performed in three batches. 


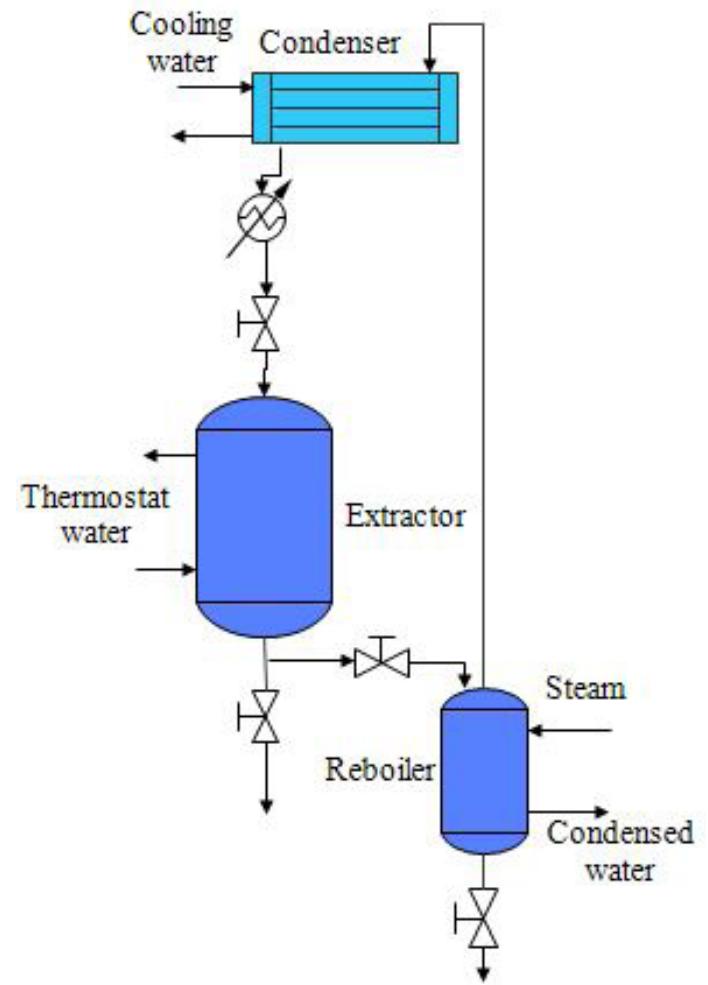

Fig. 1 Schematic figure of pilot-scale Soxhlet extractor apparatus to prepare polar hawthorn extract with $96 \%$ ethanol

\subsection{Chemical analysis}

\subsubsection{Total polyphenol content}

The total phenolic content of the drinking liquid was measured using Folin-Ciocalteu reagent according to the Hungarian pharmacopoeia [21]. $40 \mathrm{mg}$ of the dry sample extract was dissolved in $20 \mathrm{ml}$ ethanol (96\%) using ultrasonic bath. Calibration was made using pyrogallol, as reference. The polyphenol content was calculated in g pyrogallol equivalent / $100 \mathrm{~g}$ extract.

\subsubsection{Total tannin content}

The total tannin content was also determined according to the Hungarian pharmacopoeia [21]. The measurement is based on the fact, that hide powder is able to adsorb tannins. The hide powder and the dissolved extract were mixed for 1 hour using ultrasonic bath, and after filtration the non-adsorbed phenolics can be determined. The tannin content can be calculated from the difference between the total and the non-adsorbed phenolic content. The same sample concentration was used in case of determination of the total and the non-adsorbed content. The tannin content was calculated in g pyrogallol equivalent / $100 \mathrm{~g}$ extract, as well.

\subsubsection{Total flavonoid content}

Total flavonoid content was measured based on the principle that flavonoids form yellow complexes with aluminium, with an absorbance maximum at $430 \mathrm{~nm}$ [22]. $40 \mathrm{mg}$ of dry extract was dissolved in $20 \mathrm{ml}$ ethanol (96\%) using ultrasonic bath. $0.5 \mathrm{ml}$ sample solution, $1 \mathrm{ml} \mathrm{AlCl}_{3}$ solution (20 g/l, dissolved in methanol) and $1.5 \mathrm{ml}$ ethanol (96\%) were added and homogenised in a light protected cuvette. After 15 minutes the absorbance was measured. As blank a mixture of $0.5 \mathrm{ml}$ sample solution and $2.5 \mathrm{ml}$ ethanol was used: the obtained absorbance value was subtracted from the absorbance of the mixture containing the sample solution. Calibration curve was obtained using ethanolic solution of quercetin. Total flavonoid content was calculated in g quercetin equivalent / $100 \mathrm{~g}$ extract.

\subsubsection{Antioxidant capacity}

The antioxidant efficiency of the hawthorn extract was determined using DPPH (1,1-diphenyl-2-picrylhydrazyl) method, by comparing $50 \%$ inhibition value $\left(\mathrm{IC}_{50}\right)$ for the DPPH radical. $\mathrm{IC}_{50}$ is the concentration of the sample solution, when the absorbance of the sample-reagent mixture $\left(A_{1}\right)$ is the half of the absorbance of the pure reagent $\left(A_{0}\right)$. First $20 \mathrm{mg}$ of DPPH was dissolved in $50 \mathrm{ml}$ methanol and was diluted until the absorbance of the reagent solution was in the interval $0.700-0.850$. For the stock sample $10 \mathrm{mg}$ extract was dissolved in $20 \mathrm{ml}$ methanol. A dilution serial was made in light protected cuvettes using DPPH solution and sample solution. The mixtures were homogenised, and the absorbance of each was measured after exactly $30 \mathrm{~min}$ utes using methanol as blank. Quadratic polynomial was fitted to the obtained absorbance - concentration data, and the $\mathrm{IC}_{50}$ values were determined (Eq. (1)). Butylatedhydroxytoluene dissolved in methanol was used as reference

IC $(\%)=\frac{A_{0}-A_{1}}{A_{0}} \cdot 100 \%$.

\subsubsection{Identification of phenolic compounds by UPLC / QTOF-MS analysis}

The extract obtained from pilot-scale Soxhlet extraction was dissolved in $50 \%$ methanol-water. Waters ACQUITY UPLC system coupled to a Waters Xevo QTOF-MS (Waters MS Technologies, Manchester, UK) was used to analyse phenolic compounds. The UPLC instrument was equipped with a binary pump, an auto-sampler, and a column temperature controller. Waters UHPLC Acquity HSS T3 column (pore size $100 \AA$, particle size $1.8 \mu \mathrm{m}$, ID $2.1 \mathrm{~mm}$ ) was used at 
$50{ }^{\circ} \mathrm{C}$ with the flow rate of mobile phase set at $0.45 \mathrm{~mL} / \mathrm{min}$. The mobile phase consisted of (A) $0.1 \%$ formic acid in water, and (B) $0.1 \%$ formic acid in acetonitrile. A linear gradient elution program was applied as follows: 0-3 min: $5 \%$ B; 3-20 min: 5-60\% B; 20-22 min: 60-100\% B; 22-23 min: $100-5 \% \mathrm{~B} ; 23-27 \mathrm{~min}: 5 \% \mathrm{~B}$. The sample injection volume was $3 \mu \mathrm{L}$. The mass spectrometer was scanning from 80 to $1200 \mathrm{~m} / \mathrm{z}$, the cone voltage was set to $35 \mathrm{~V}$ and the capillary voltage to 2.5 and $3.0 \mathrm{kV}$ for negative ESI mode. The desolvation gas flow rate was $800 \mathrm{~L} / \mathrm{h}$ at a temperature of $550{ }^{\circ} \mathrm{C}$ and the cone gas flow rate was $40 \mathrm{~L} / \mathrm{h}$. The source temperature was $120{ }^{\circ} \mathrm{C}$. MSe was performed with collision energy ramped from 15 to $50 \mathrm{eV}$. MassLynx 4.1 (Waters MS Technologies) was used to control the system and acquire the data. The method for the analysis was developed and the investigation was performed in Green Technology Group of Lund University, Sweden.

\subsection{Drinking test}

The drinking test was performed in September 2016 at the poultry farm of Hegyháti Broiler Kft., Hegyhátsál, Hungary. Totally more than 90000 broiler chickens (approx. $2350 \mathrm{~g}$ expected weight at $39^{\text {th }}$ day) were settled in August 2016. 100 of them were randomly chosen and separated from the stock, as an experimental group at age of 32 days. All chickens were reared in the same way: the same forage and feed were used. Regarding the rearing the only difference was the drinking the tincture containing the hawthorn extract.

From the $32^{\text {nd }}$ lifeday of the chickens for one week the experimental group drank the hawthorn tincture (final concentration of the drinking tincture: approx. $3.75 \mathrm{~g} / \mathrm{L}$ dry extract content, approx. $7.37 \mathrm{~g} / \mathrm{L}$ ethanol content).

The tincture was prepared from the concentrate obtained with the pilot scale Soxhlet extraction. The preheated concentrate (approx. 2.1 liter, containing ethanol (737.3 g/L) and dry extract (374.5 g/L)) was dissolved in tap water, getting 21 liter solution (ethanol content: $73.7 \mathrm{~g} / \mathrm{L}$, dry extract content: $37.5 \mathrm{~g} / \mathrm{L}$ ). During the dilution, two aspects were considered: complete dissolution of the concentrate and minor ethanol content in the final product. LUPRO-CID, (0.098 v/v\%), generally used disinfective in poultry industry, was also added to the solution. The water of the control group contained the same concentration of the disinfectant. During the dissolution of the extract a flocculent precipitate formed, which was non-filterable due to the clogging of the filter paper. Therefore, the two-phase solution was centrifuged (1500 1/min, $5 \mathrm{~min}$ ) and the pure supernatant was separated with a relatively low amount of loss. This product was diluted 10 times volume for the chickens in the poultry farm.

The slaughtering was performed at the $40^{\text {th }}$ lifeday. At the end of the rearing the chickens from the experimental group were collected separately. As a control group, 100 chickens were randomly chosen from the nontreated stock. Each step of the poultry processing was conducted the same way in case of the two groups, as well. The chickens were stunned using electrical water bath (parameters of shocking: $140 \mathrm{~mA}, 399 \mathrm{~Hz}$ ) before slaughtering. The extent of the blood spots in the chicken breast - appearing during the procession - was compared visually and on the basis of the quantity of the removed low value meat between the treated and the control group. The observed differences were confirmed with statistical tests.

\section{Results and discussion}

\subsection{Preparation of hawthorn berry extracts and drinking tincture}

The air-dried and grinded berries were processed in three steps to get a tincture, used in a drinking experiment for chickens. Supercritical fluid extraction with $\mathrm{CO}_{2}$ was carried out to reduce the amount of oily components in the berries. With this pretreatment, the formation of emulsion can be decreased during further extraction step with polar solvent. The obtained extraction curves level out (Fig. 2). Brunner-equations were fitted to the experimental data (Eq. (2)). Both the kinetic parameter $(k)$ and the yield $(Y)$ are very similar in case of the two experiments. Nearly the maximal yield among these conditions, calculated from the fitted curve $(2.5 \%)$ was achieved with $14 \mathrm{~kg} \mathrm{CO} / \mathrm{kg}$ dry material (approx. after 180 minutes). To increase the yield, after this time the system was kept under pressure for 1 hour, but the amount of the obtained extract was only slightly increasing (approx. with $0.1 \%$ )

$Y=Y_{\infty} \cdot\left(1-\exp \left(-k \cdot \frac{m_{\mathrm{CO}_{2}}}{m_{\text {dry material }}}\right)\right)$.

The first, high-slope part of the extraction curve shows the apparent solubility (7.8 and $8.2 \mathrm{~g}$ dry oil / $\mathrm{kg} \mathrm{CO}$ ), which depends on the hawthorn and also on the conditions of the extraction. The second part of the curve is determined by diffusion in the solid phase, which most likely limits the rate of the extraction. The appearance of the extracts changed during the process from yellow to dark brown color with a fatty, creamy texture. 


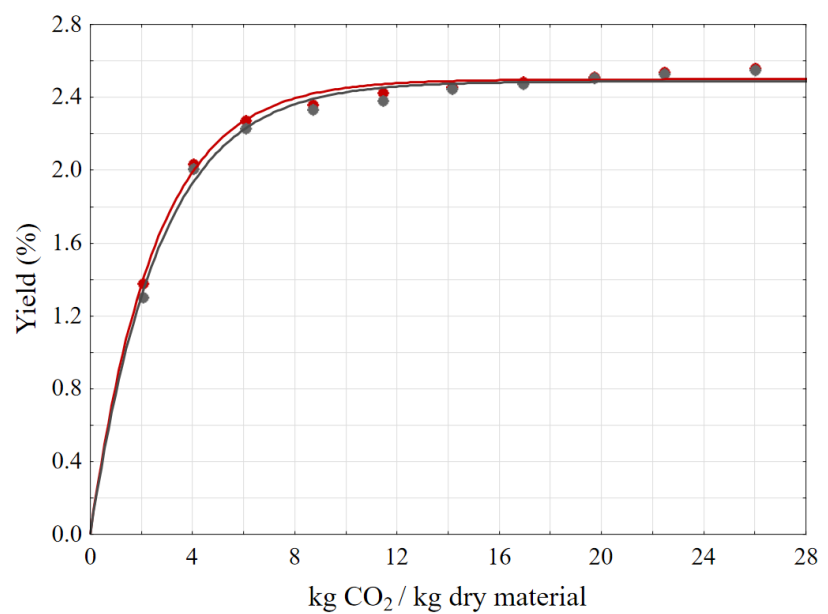

Fig. 2 Extraction curves of hawthorn berries obtained with supercritical fluid extraction (extractor pressure and temperature: $45 \mathrm{MPa}, 50{ }^{\circ} \mathrm{C}$, separator pressure $4 \mathrm{MPa}, 40^{\circ} \mathrm{C}$ ). Yield is given in percentage, $\mathrm{g}$ dry extract / $100 \mathrm{~g}$ dry plant.

The plant residue of the supercritical fluid extraction was processed with a pilot-scale Soxhlet extractor to obtain polar compounds, such as polyphenols, antioxidants. These are believed to be important for the cardiovascular applications. The extraction yield referred to dry material is $25.9 \pm 3.0 \mathrm{~m} / \mathrm{m} \%$ based on three replications. Totally approx. 2.1 liter hawthorn concentrate was obtained.

\subsection{Determination of total bioactive content and the antioxidant capacity}

Total bioactive compounds were determined in the pilotscale Soxhlet extract expressed in pyrogallol and quercetin equivalents. The contents of the plant material can be calculated with the extraction yield, obtained from the pilotscale Soxhlet experiment. As shown in Table 1, the flavonoid activity is very low compared to the tannins. This corresponds to the fact, that flavonoids are the major component of the flowers, not of the berries [23, 24]. A comparison can be made with the experiments of Froehlicher et al. [25]. The polyphenol content of the berry in this experiment is slightly lower than in the cited paper $(0.83 \% /$ $1.28 \%$ ), while the tendency is reversed in case of the tannins $(0.19 \% / 0.10 \%)$. Chang et al. [26] however measured much higher amount of total polyphenol and flavonoid content of hawthorn extract made with ethanol $(17.4 \pm 1.4 \mathrm{~g}$ gallic acid equivalent / $100 \mathrm{~g}$ extract and $0.88 \pm 0.64 \mathrm{~g}$ quercetin equivalent / $100 \mathrm{~g}$ extract, respectively), however the yield of the extraction using sonication was lower in their case $(14.7 \pm 1.3 \%$ vs. $25.9 \pm 3.0 \%)$. The antioxidant capacity is compared according to $\mathrm{IC}_{50}$ values: lower $\mathrm{IC}_{50}$ value
Table 1 Total polyphenol, tannin, flavonoid contents of the hawthorn extract and the plant, using pyrogallol and quercetin equivalent as reference (PE\%, QE\%: g reference equivalent / $100 \mathrm{~g}$ extract or $100 \mathrm{~g}$ dry plant) and the antioxidant efficiency of the extract using butylated hydroxytoluene (BHT) as reference.

\begin{tabular}{lcc}
\hline \multicolumn{3}{c}{ Total bioactive compound contents } \\
\hline & $\begin{array}{c}\text { Pilot-scale } \\
\text { Soxhlet extract }\end{array}$ & Plant material \\
\hline Phenolic content (PE\%) & $3.220 \pm 0.031$ & $0.834 \pm 0.008$ \\
Tannin content (PE\%) & $0.736 \pm 0.047$ & $0.191 \pm 0.012$ \\
Flavonoid content (QE\%) & $0.100 \pm 0.004$ & $0.026 \pm 0.001$ \\
\hline Antioxidant capacity $(\mu \mathrm{g} / \mathrm{ml})$ & \\
\cline { 1 - 2 } Pilot-scale Soxhlet extract & $55.00 \pm 1.82$ & \\
BHT reference & $18.71 \pm 1.67$ & \\
\hline
\end{tabular}

means higher antioxidant capacity. Table 1 shows that $50 \%$ inhibition was reached at $55.00 \mu \mathrm{g} / \mathrm{ml}$ extract concentration. This shows the extract is an efficient natural antioxidant, $\mathrm{IC}_{50}$ value is only three times higher than that of the synthetic and chemically pure BHT used as reference.

\subsection{Determination of the main compounds of the pilot- scale Soxhlet extract by UPLC / QTOF-MS analysis}

The obtained chromatograms were evaluated by comparing the results to literature data on the basis of previously reported compounds in haw thorn and the most commonly identified phenolic compounds in other plants. The exact $\mathrm{m} / \mathrm{z}$ values for both intact compounds and fragments (MS/ MS) were taken into consideration during chemical identification. The tentatively identified compounds are listed in Table 2.

Two phenolic acids were detected with the same mass $(\mathrm{m} / \mathrm{z}: 353.086)$. These were identified as two isomers of caffeoylquinic acid. According to literature 3-O- and 5-O- caffeoylquinic acid isomers are the most common in Crataegus species, and the 3-O form has lower retention time [27].

Besides several dimer and oligomer forms of procyanidins, monomeric form ( $\mathrm{m} / \mathrm{z}: 289.071)$ was detected, as well. It is assumed that catechin or epicatechin, and associated dimer $(\mathrm{m} / \mathrm{z}: 577.135)$, trimer $(\mathrm{m} / \mathrm{z}: 865.198)$ and tetramer $(\mathrm{m} / \mathrm{z}: 1153.256)$ forms were also identified as major phenolic components. According to the literature the most abundant compounds in hawthorn berries are the B-type procyanidins [28]. At $\mathrm{m} / z$ of 739.170 , another procyanidin was detected, considered to be dimeric procyanidin connected with one hexose group. This component has also been reported previously [29]. 
Table 2 The obtained $m / z$ values and main MS/MS fragments of pilot-scale Soxhlet extract in negative ion mode using UPLC-QTOF-MS/MS

\begin{tabular}{|c|c|c|c|c|c|}
\hline No. & $\begin{array}{l}\text { Ret. time } \\
\quad(\min )\end{array}$ & Experim. $m / z$ & $\begin{array}{l}\text { Theor. } \\
m / z\end{array}$ & $\begin{array}{l}\text { MS/MS fragments } \\
\text { (Experim.) }\end{array}$ & $\begin{array}{l}\text { Compound name } \\
\text { (tentative id.) }\end{array}$ \\
\hline 1 & 2.87 & 353.097 & 353.088 & $\begin{array}{l}191.057, \\
179.039\end{array}$ & $\begin{array}{l}\text { Caffeoylquinic } \\
\text { acid }\end{array}$ \\
\hline 2 & 3.99 & 353.097 & 353.088 & $\begin{array}{l}191.057, \\
179.039\end{array}$ & $\begin{array}{l}\text { Caffeoylquinic } \\
\text { acid }\end{array}$ \\
\hline 3 & 4.21 & 353.097 & 353.088 & $\begin{array}{l}191.057, \\
179.039\end{array}$ & $\begin{array}{l}\text { Caffeoylquinic } \\
\text { acid }\end{array}$ \\
\hline 4 & 4.35 & 577.151 & 577.135 & $\begin{array}{l}407.087, \\
289.079\end{array}$ & $\begin{array}{l}\text { Procyanidin } \\
\text { dimer }\end{array}$ \\
\hline 5 & 4.53 & 577.151 & 577.135 & $\begin{array}{l}407.087, \\
289.079\end{array}$ & $\begin{array}{l}\text { Procyanidin } \\
\text { dimer }\end{array}$ \\
\hline 6 & 5.01 & 289.079 & 289.071 & 245.087 & (Epi)catechin \\
\hline 7 & 5.51 & 865.221 & 865.199 & $\begin{array}{l}407.087, \\
289.078\end{array}$ & $\begin{array}{l}\text { Procyanidin } \\
\text { trimer }\end{array}$ \\
\hline 8 & 5.80 & 1153.290 & 1153.258 & $\begin{array}{l}289.077 \\
125.027\end{array}$ & $\begin{array}{l}\text { Procyanidin } \\
\text { tetramer }\end{array}$ \\
\hline 9 & 6.52 & 739.188 & 739.188 & $\begin{array}{l}289.078 \\
125.026\end{array}$ & $\begin{array}{l}\text { Procyanidin dimer } \\
\text { monoglycoside }\end{array}$ \\
\hline 10 & 6.99 & 609.163 & 609.146 & 301.040 & Rutin \\
\hline 11 & 7.19 & 463.100 & 463.098 & $\begin{array}{l}301.040, \\
300.035\end{array}$ & $\begin{array}{l}\text { Quercetin } \\
\text { 3-O-hexoside }\end{array}$ \\
\hline 12 & 7.38 & 463.100 & 463.098 & $\begin{array}{l}301.040 \\
300.035\end{array}$ & $\begin{array}{l}\text { Quercetin } \\
\text { 3-O-hexoside }\end{array}$ \\
\hline 13 & 8.51 & 477.104 & 477.117 & $\begin{array}{l}314.049 \\
271.029\end{array}$ & $\begin{array}{l}\text { Isorhamnetin } \\
\text { O-hexoside }\end{array}$ \\
\hline 14 & 8.70 & 477.104 & 477.117 & $\begin{array}{l}314.049 \\
271.029\end{array}$ & $\begin{array}{l}\text { Isorhamnetin } \\
\text { O-hexoside }\end{array}$ \\
\hline 15 & 9.42 & 619.184 & 619.167 & $\begin{array}{l}413.099 \\
293.054\end{array}$ & Cratenacin (isomer) \\
\hline
\end{tabular}

Flavonoids were observed in glycoside forms. Among them the most intense peak $(\mathrm{m} / \mathrm{z}: 463.087)$ which was identified as quercetin 3-O-hexoside. Compound No. 11 was proposed as quercetin 3-O-galactoside (hyperoside), while compound No. 12 as quercetin 3-O-glucoside relying on the mass and the order of the retention times [29]. This corresponds to previously reported high amount of hyperoside in hawthorn berries [30, 31]. No. 13 and $14(\mathrm{~m} / \mathrm{z}: 447.103)$ were assigned as isorhamnetin O-galactoside and glucoside, respectively. Compound 13 and 14 were identified based on the MS/MS data, since more compounds with these masses were identified earlier in the berries [29].

The goal of the chemical identification of the important polar components of the extract was not to identify novel bioactive compounds in hawthorn berries, but rather to give a qualitative characterization of the special extract prepared for the drinking experiment.

\subsection{Drinking experiment}

No difference was observed during the rearing period in the drinking or other behavior of the chicken. Some chickens do not reach their desired age of 42 days, however no death was observed during the early morning transportation to the slaughter house. The death rate of the chickens was studied in order to observe any difference induced by the treatment. In the treated group the death rate of the rearing was $7 \%$ - slightly higher compared to the total death rate $(5.75 \%)$. By comparing the death rates with chisquared test using $2 \times 2$ contingency table, however, the difference appears to be non-significant at significance level of $0.05\left(\chi_{0}^{2}=1.84, p=0.1747\right)$ [32].

Moreover, according to post-mortem examination the cause of death are similar in the two groups, most frequently cardiac reasons, due to the warm weather conditions in summer. Therefore, the death rate is not supposed to be affected by the treatment. 


\subsubsection{Visual comparison of chicken breasts}

Chicken breasts of both the treated and the control group were examined by a member of the Quality Control Department at the poultry processing site. The meats were classified in four roughly defined groups: no blood spots, small extent blood spots, medium-size blood spots and large extent blood spots (Fig. 3).

Noticeable improvement was achieved regarding the size of the blood spots. The number of chicken breasts, without blood spots, increased by more than $50 \%$, while in the other groups, the number of the chicken breasts decreased. The difference was confirmed with statistical analysis. In our case the dependent variable can be measured on an ordinal scale, because we only know that no blood spots is better than small extent blood spots, which is better than medium-size blood spots, and so on, but numeric value cannot be assigned to each level.

Thus logistic regression was applied to investigate on the difference of the extent of the blood spots in the chicken breasts between the treated and the control group. The model is based on the logit function of the cumulative probabilities of the number of chicken breasts up to and including a given "blood spots" category [33]. The results showed that the drinking treatment significantly decreased the extent of the blood spots $(p=0.00376)$.

\subsubsection{Comparing the amount of the removed meat}

During the procedure those parts of the chicken breast, where the blood spots appeared were removed. Comparing the amount of this "cut off meat" is an especially important aspect, since the low value of this product cause huge financial loss for the poultry processing company. Regarding the quantities, large improvement was achieved. In case of the treated group $7.74 \%$ of the full meat weight was removed, while in the control group this value was $21.39 \%$.

\subsubsection{Comparing the weight of the chicken breast}

The weight of the chicken breasts was also registered during the process. The meats (already cut in half, as a step of the procedure) were grouped in ranges of $10^{-2}$ kilograms and the numbers of meats in each group were determined (Fig. 4).

The weights of the chicken breasts in the treated group are in average lower than in the control group. This might be the effect of the treatment; however these lower weights are still in the optimal range. Moreover, the distribution of the weights is tighter in the treated group, which is a preference in the poultry processing technology.

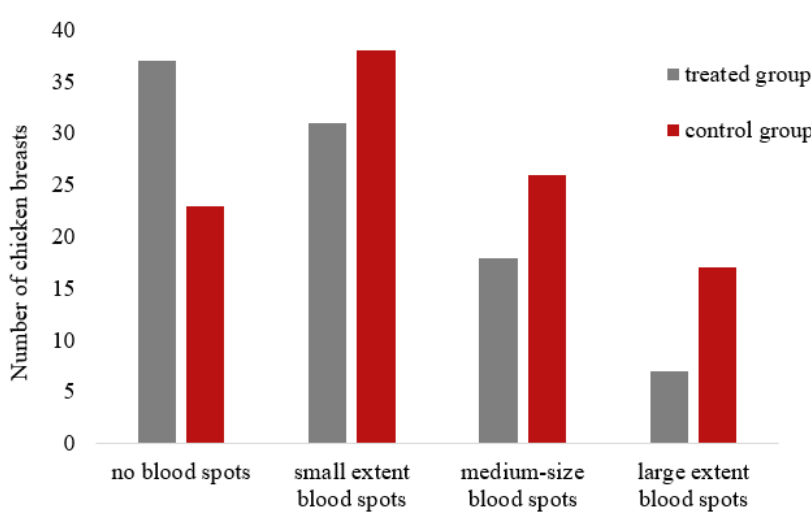

Fig. 3 Number of chicken breasts classified visually in four roughly defined groups in case of both the treated and the control group.

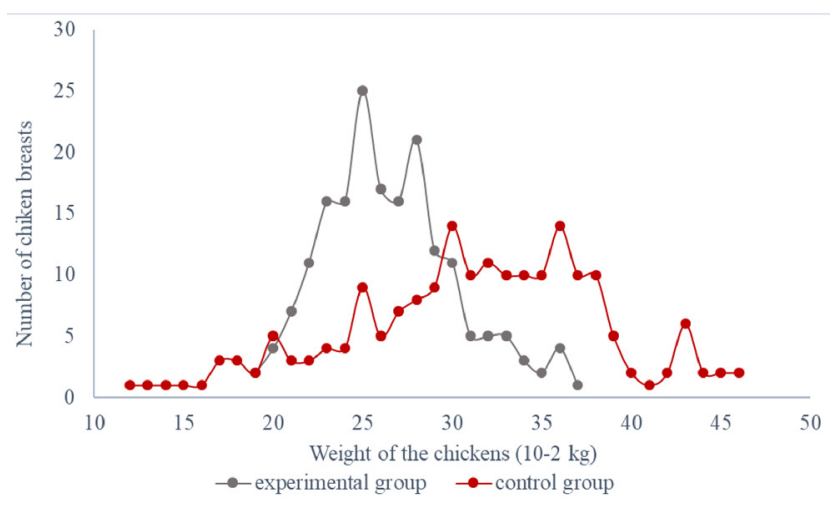

Fig. 4 Half chicken breasts classified in weight ranges, in case of the treated and the control group.

The difference of the two groups in the weight of chicken breasts was verified with statistical evaluation, as well. Non-parametric Mann-Whitney test was applied, because the obtained data do not follow clearly normal distribution (especially in the treated group) (Figs. 5 and 6). Assuming the same shape of the two distributions it was proved at level of 0.05 , that the medians of the weight for the two groups differed significantly $\left(z_{0}=7.656, p<0.000\right)$.

\section{Conclusions}

Hawthorn berry, which is a wildly grown and easily available plant of the region, has a potential in the livestock sector. The extracts of the berries have positive effects on the cardiovascular system of poultry. The amount of the removed meat decreased significantly in the experimental group. However the decreasing weight of the meat needs to be taken into consideration, as well.

The total polyphenol and tannin contents are relatively high in the berries and in the extracts, the results roughly corresponds to already reported values, however as expected in the berries according to literature the 


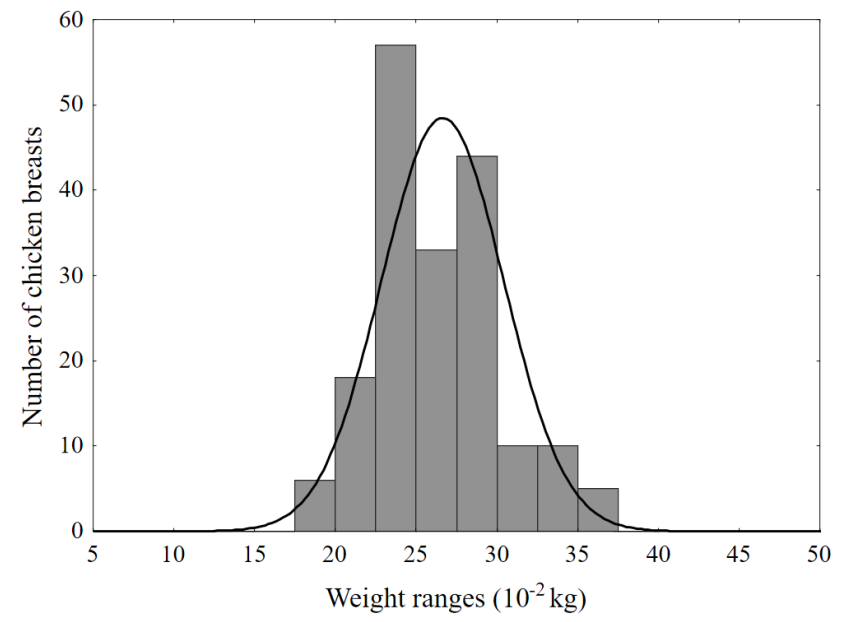

Fig. 5 Weight distribution of the chicken breasts in the treated group

flavonoid content is low. The extract showed good antioxidant properties, while the drinking tincture itself had $3.75 \mathrm{~g} / \mathrm{L}$ dry extract content. By analyzing the main compounds, several phenolic acids, procyanidin dimers and oligomers and flavonoids were detected.

\section{Acknowledgement}

This work was supported by the Higher Education Excellence Program of the Ministry of Human Capacities in the frame of Biotechnology research area of Budapest

\section{References}

[1] Wang, J., Xiong, X., Feng, B. "Effect of Crataegus Usage in Cardiovascular Disease Prevention: An Evidence-Based Approach", Evidence-Based Complementary and Alternative Medicine, 2013, article number: 149363, 2013.

https://doi.org/10.1155/2013/149363

[2] Chang, W.-T., Dao J., Shao, Z.-H. "Hawthorn: Potential Roles in Cardiovascular Disease", The American Journal of Chinese Medicine, 33(1), pp. 1-10, 2015. https://doi.org/10.1142/S0192415X05002606

[3] Chang, Q., Zuo, Z., Harrison, F., Chow, M. S. S. "Hawthorn", The Journal of Clinical Pharmacology, 42(6), pp. 605-612, 2002. https://doi.org/10.1177/00970002042006003

[4] Arvanitoyannis, I. S., Varzakas, T. H. "9 - Fruit / Fruit Juice Waste Management: Treatment Methods and Potential Uses of Treated Waste", In: Arvanitoyannis, I. S. (eds.) Waste Management for the Food Industries: Food Science and Technology, Academic Press, Oxford, 2008, pp. 569-628.

https://doi.org/10.1016/B978-012373654-3.50012-2

[5] Azmir, J., Zaidul, I. S. M., Rahman, M. M., Sharif, K. M., Mohamed, A., Sahena, F., Jahurul, M. H. A., Ghafoor, K., Norulaini, N. A. N., Omar, A. K. M. "Techniques for extraction of bioactive compounds from plant materials: A review", Journal of Food Engineering, 117(4), pp. 426-436, 2013. https://doi.org/10.1016/j.jfoodeng.2013.01.014

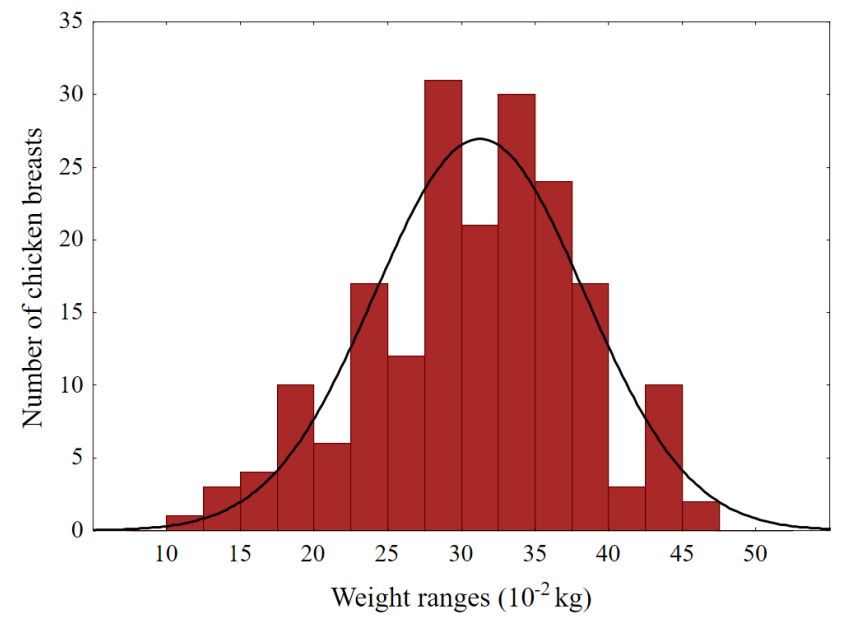

Fig. 6 Weight distribution of the chicken breasts in the control group

University of Technology and Economics (BME FIKPBIO). The investigation of the phenolic compounds was performed in Green Technology Group of Lund University, Sweden, where M.K. spent nine weeks financed by the Erasmus ${ }^{+}$programme of the EU, and co-financed by C.T. grants from the Swedish Research Council Formas (2016-00604 and 222-2014-1924). The drinking test was performed in the poultry farm of Hegyháti Broiler Kft, Hungary. Extraction experiments were performed and evaluated at BME.

[6] Yang, B., Liu, P. "Composition and health effects of phenolic compounds in hawthorn (Crataegus spp.) of different origins", Journal of the Science of Food and Agriculture, 92(8), pp. 1578-1590, 2012. https://doi.org/10.1002/jsfa.5671

[7] Ye, X.-L., Huang, W.-W., Chen, Z., Li, X.-G., Li, P., Lan, P., Wang, L., Gao, Y., Zhao Z.-Q., Chen, X. "Synergetic Effect and Structure-Activity Relationship of 3-Hydroxy-3-methylglutaryl Coenzyme A Reductase Inhibitors from Crataegus pinnatifida Bge.", Journal of Agricultural and Food Chemistry, 58(5), pp. 3132-3138, 2010.

https://doi.org/10.1021/jf903337f

[8] Nabavi, S. F., Habtemariam, S., Ahmed, T., Sureda, A., Daglia, M., Sobarzo-Sánchez, E., Nabavi, S. M. "Polyphenolic Composition of Crataegus monogyna Jacq.: From Chemistry to Medical Applications", Nutrients, 7(9), pp. 7708-7728, 2015. https://doi.org/10.3390/nu7095361

[9] Simirgiotis, M. J. "Antioxidant Capacity and HPLC-DAD-MS Profiling of Chilean Peumo (Cryptocarya alba) Fruits and Comparison with German Peumo (Crataegus monogyna) from Southern Chile", Molecules, 18(2), pp. 2061-2080, 2013. https://doi.org/10.3390/molecules18022061

[10] Watson, R. R., Preedy, V. R. "Botanical Medicine in Clinical Practice", 1st ed., CABI Publishing, Wallingford, UK, 2008. https://doi.org/10.1079/9781845934132.0000 
[11] "Council regulation (EC) No 1099/2009 of 24 September 2009 on the protection of animals at the time of killing", Official Journal of the European Union, 52, pp. L 303/1 - L 303/30, 2009.

[12] HSA Guidance Notes No 7 "Electrical Waterbath Stunning of Poultry", [pdf] Humane Slaughter Association, Wheathampstead, UK, Available at: https://www.hsa.org.uk/downloads/ hsagn7electricalwaterbathpoultryl.pdf [Accessed: 27 June 2018]

[13] Barros, L., Carvalho, A. M, Ferreira, C. F. R. "Comparing the composition and bioactivity of Crataegus Monogyna flowers and fruits used in folk medicine", Phytochemical Analysis, 22(2), pp. 181$188,2011$.

https://doi.org/10.1002/pca.1267

[14] Kubovics, M., Al-Hamimi, S., Huszár, Gy., Turner, C., Székely, E. "Extracting and Analysing Non-polar Components of Hawthorn Berries", presented at Application of Supercritical Fluids 2018, Budapest, Hungary, May, 17, 2018.

[15] Abbas, K. A., Mohamed, A., Abdulamir, A. S., Abas, H. A. "A Review on Supercritical Fluid Extraction as New Analytical Method", American Journal of Biochemistry and Biotechnology, 4(4), pp. 345-353, 2008.

https://doi.org/10.3844/ajbbsp.2008.345.353

[16] Sovilj, M. N., Nikolovski, B. G., Spasojević, M. Đ. "Critical review of supercritical fluid extraction of selected spice plant materials", Macedonian Journal of Chemistry and Chemical Engineering, 30(2), pp. 197-220, 2011.

[17] Weibel, G. L., Ober, C. K. "An overview of supercritical $\mathrm{CO}_{2}$ applications in microelectronics processing", Microelectronic Engineering, 65(1-2), pp. 145-152, 2003. https://doi.org/10.1016/S0167-9317(02)00747-5

[18] Oszagyán, M., Simándi, B., Sawinsky, J., Kéry, Á., Lemberkovics, E., Fekete, J. "Supercritical Fluid Extraction of Volatile Compounds from Lavandin and Thyme", 11(3), pp. 157-165, 1996. https://doi.org/10.1002/(SICI)1099-1026(199605)11:3<157::AIDFFJ559>3.0.CO;2-6

[19] Kery, A., Ronyai, E., Simandi, B., Lemberkovics, E., Keve, T., Deak, A., Kemény, S. "Recovery of a bioactive sesquiterpene lactone from Tanacetum parthenium by extraction with supercritical carbon dioxide", Chromatographia, 49(9-10), pp. 503-508, 1999. https://doi.org/10.1007/BF02467749

[20] Calvo, A., Morante, J., Plánder, Sz., Székely, E. "Fractionation of biologically active components of grape seed (Vitis vinifera) by supercritical fluid extraction", Acta Alimentaria, 46(1), pp. 27-34, 2017. https://doi.org/10.1556/066.2017.46.1.4

[21] "VIII. Magyar Gyógyszerkönyv" (Hungarian pharmacopoeia), 8th ed., Országos Gyógyszerészeti Intézet, Budapest, Hungary, 2006. (in Hungarian)

[22] Höltzlné Plánder, Sz. "Gyógynövénykivonatok antioxidáns hatásának jellemzése" (Analysis of antioxidant efficiency of herbs), PhD Dissertation, Budapest University of Technology and Economics, 2015. (in Hungarian)
[23] Bone, K., Mills, S. "Principles and Practice of Phytotherapy", 2nd ed., Churchill Livingstone, London, UK, 2012.

[24] Liu, P., Kallio, H., Yang, B. "Phenolic Compounds in Hawthorn (Crataegus grayana) Fruits and Leaves and Changes during Fruit Ripening", Journal of Agricultural and Food Chemistry, 59(20), pp. 11141-11149, 2011. https://doi.org/10.1021/jf202465u

[25] Froehlicher, T., Hennebelle, T., Martin-Nizard, F., Cleenewerck, P., Hilbert, J.-L., Trotin, F., Grec, S. "Phenolic profiles and antioxidative effects of hawthorn cell suspensions, fresh fruits, and medicinal dried parts", Food Chemistry, 115(3), pp. 897-903, 2009. https://doi.org/10.1016/j.foodchem.2009.01.004

[26] Chang, C. L., Chen, H. S., Shen, Y. C., Lai, G. H., Lin, P. K., Wang, C. M. "Phytochemical composition, antioxidant activity and neuroprotective effect of Crataegus pinnatifida fruit", South African Journal of Botany, 88, pp. 432-437, 2013.

https://doi.org/10.1016/j.sajb.2013.08.017

[27] Rodrigues, S., Calhelha, R. C., Barreira, J. C. M., Dueñas, M., Carvalho, A. M., Abreu, R. M. V, Santos-Buelga, C., Ferreira I. C. F. R. "Crataegus monogyna buds and fruits phenolic extracts: Growth inhibitory activity on human tumor cell lines and chemical characterization by HPLC-DAD-ESI/MS", Food Research International, 49(1), pp. 516-523, 2012. https://doi.org/10.1016/j.foodres.2012.07.046

[28] Yang, B., Liu, P. "Composition and health effects of phenolic compounds in hawthorn (Crataegus spp.) of different origins", Journal of the Science of Food and Agriculture, 92(8), pp. 1578-1590, 2012.

https://doi.org/10.1002/jsfa.5671

[29] Karar, M. G. E., Kuhnert, N. "UPLC-ESI-Q-TOF-MS/MS Characterization of Phenolics from Crataegus monogyna and Crataegus laevigata (Hawthorn) Leaves, Fruits and their Herbal Derived Drops (Crataegutt Tropfen)", Journal of Chemical Biology and Therapeutics, 1(1), article number: 1000102, 2015. https://doi.org/10.4172/2572-0406.1000102

[30] Jurikova, T., Sochor, J., Rop, O., Mlcek, J., Balla, S., Szekeres L., Adam, V., Kizek, R. "Polyphenolic Profile and Biological Activity of Chinese Hawthorn (Crataegus pinnatifida BUNGE) Fruits", Molecules, 17(12), pp. 14490-14509, 2012. https://doi.org/10.3390/molecules171214490

[31] Tassell, M. C., Kingston, R., Gilroy, D., Lehane, M., Furey, A. "Hawthorn (Crataegus spp.) in the treatment of cardiovascular disease", Pharmacognosy Review, 4(7), pp. 32-41, 2010. https://doi.org/10.4103/0973-7847.65324

[32] Agresti, A. "Categorical Data Analysis", 2nd ed., John Wiley \& Sons, Inc., Hoboken, NJ, USA, 2002. https://doi.org/10.1002/0471249688

[33] McCullagh, P., Nelder, J. A. "Generalized Linear Models", 2nd ed., Chapman and Hall, Boca Raton, FL, USA, 1989. 